\title{
Current and future invasion potential of Senna didymobotrya under the changing climate in Africa
}

\author{
Elias Cherenet Weldemariam ${ }^{1}$ and Sintayehu Dejene ${ }^{1}$ \\ ${ }^{1}$ Haramaya University
}

October 9, 2020

\begin{abstract}
Climate change is thought to facilitate the introduction and spread of invasive alien species. The present study aimed at examining the present and future invasive potential of S. didymobotrya under the changing climatic conditions using the Species Distribution Model. Two representative concentration pathways (RCP4.5, and RCP8.5), and seven bioclimatic including one topographic variable were used to simulate the current and future (2050s and 2070s) distribution of S. didymobotrya invasion in Africa. The model performance evaluation is done based on, the area under the receiver operating characteristic curve (AUC) and true skills statistics (TSS). The results of the study showed that under current climatic conditions $18 \%$ of the continent of Africa is suitable for S. didymobotrya establishment and invasion. Eastern Africa is seen as the most suitable habitats for S. didymobotrya invasion followed by southern Africa. The predicted model shows that in the 2050s under RCP4.5 and RCP8.5, $3.4 \%$ and $3.17 \%$ of the continent will be highly suitable for S. didymobotrya invasion, respectively. In the 2070 s, the highly suitable area for the species is predicted to be $3.18 \%$ and $2.73 \%$ in RCP4.5 and RCP 8.5 , respectively. The low to moderate suitability under RCP 4.5 and RCP 8.5 in the 2050s is projected as $17.4 \%$ and $20.5 \%$ and this area is increased in the 2070 s to $19.11 \%$ and 22.82 for the RCP 4.5 and RCP 8.5, respectively. The results of this study indicate a significant increase in the vulnerability of habitat for S. didymobotrya invasion under the future climatic conditions. Our current finding suggests the future biodiversity conservation strategy and policy direction should focus on the means and strategy of limiting the rate of expansion of invasion and distribution.
\end{abstract}

\section{Hosted file}

Manuscript_senna__Rev_October2020.pdf available at https://authorea.com/users/347998/ articles/485690-current-and-future-invasion-potential-of-senna-didymobotrya-under-thechanging-climate-in-africa

\section{Hosted file}

Figure and table.pdf available at https://authorea.com/users/347998/articles/485690-currentand-future-invasion-potential-of-senna-didymobotrya-under-the-changing-climate-in-africa 